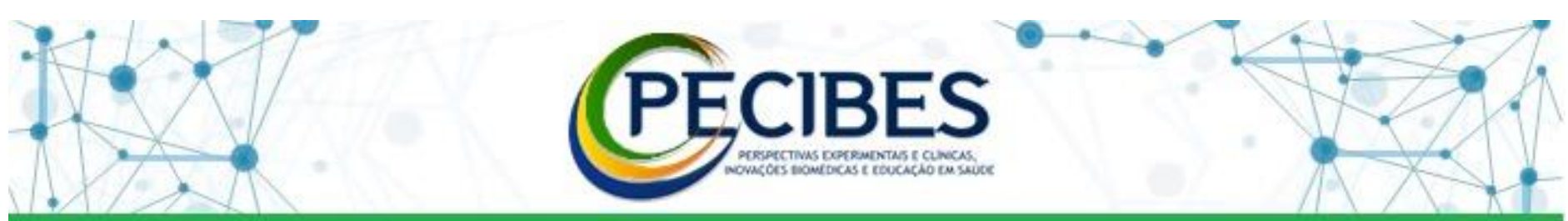

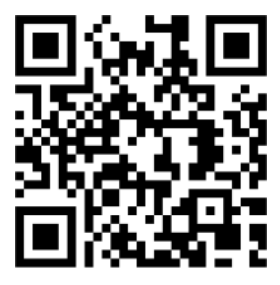

http://www.seer.ufms.br/i ndex.php/pecibes/index

*Autor
correspondente:
Sarah Larrosa
Unilvarsidade
Federal de
Grosso do $r$ Sul
UFMS. E-mail do
autor
sarahlarrosa@hotma
il.com

Descritores: Préeclâmpsia.

Hipertensão Arterial. Hipertensão Induzida pela Gravidez

Key-words: Pre eclampsia. Hypertension. Pregnancy-Induced Hypertension.

Descriptores:

Preeclampsia.

Hipertensión.

Hipertensión

Inducida

en el Embarazo.

\section{Cuidado de enfermagem na pré-eclâmpsia sobreposta à hipertensão crônica: um relato de experiência}

Nursing care in overlapping pre-eclampsia to the chronic hypertension: an experience report

Sarah Larrosa Silva ${ }^{1}$, Gabriella Figueiredo Marti ${ }^{1}$, Ana Paula de Assis Sales ${ }^{2}$

1. Graduanda em Enfermagem. Universidade Federal de Mato Grosso do Sul. Campo Grande, Mato Grosso do Sul, Brasil.

2. Enfermeira. Departamento de Enfermagem da Universidade Federal de Mato Grosso do Sul, Instituto Integrado de Saúde. Campo Grande, Mato Grosso do Sul, Brasil.

Introdução: a pré-eclâmpsia é uma das complicações da Síndrome Hipertensiva Específica da Gestação (SHEG) e quando sobreposta à hipertensão crônica, intensificada pelo processo fisiológico da gestação resultante do aumento do volume plasmático materno, acentua ainda mais o risco de morbimortalidade materno-fetal. Objetivo: relatar a assistência de enfermagem no processo de cuidar a uma gestante com pré-eclâmpsia. Material e método: trata-se de relato de experiência, desenvolvido durante a prática específica de uma disciplina curricular, que contou com a escolha de um caso clínico e acompanhamento de uma gestante com a SHEG, utilizando a Sistematização da Assistência de Enfermagem (SAE) e a análise documental do prontuário para avaliar os seguintes dados: história clínica pregressa, exames laboratoriais, evolução diária por meio da elaboração dos diagnósticos de enfermagem e evolução diante das intervenções de enfermagem. Resultados: a tríade clássica de sintomas manifestada (hipertensão arterial, edema e proteinúria) exibe a proteinúria como patognomônica desta SHEG, evidenciada principalmente pelo exame de relação entre proteina e creatinina $\geq 0,3$, além da sobreposição da hipertensão crônica ao aumento de pressão desencadeado pela préeclâmpsia. A SAE permite elaborar um processo de enfermagem centrado nas respostas humanas e necessidades à saude de forma holística/individual. As evidências científicas apontam a SHEG como a primeira causa de internações e mortes no ciclo gestatório, assim, o enfermeiro deve apropriar-se do conhecimento clínico-epidemilógico para monitorar, na Rede de Atenção a Saúde, mulheres nesta condição, atentando-se aos fatores preditores de risco (hipertensão crônica, obesidade e diabetes mellitus, por exemplo). Conclusões: portanto, entende-se que a hipertensão prévia propicia o aumento da permeabilidade capilar, que culmina no edema, seguida pela hemoconcentração que possibilita a redução da taxa de filtração glomerular provocando a proteinuria, evoluindo para outras complicações que podem ser monitoradas pela SAE. 